\title{
HUBUNGAN PAJANAN BISING KONTINYU TROMOL EMAS DENGAN KELUHAN DISPEPSIA PADA MASYARAKAT DESA TATELU
}

\author{
${ }^{1}$ Bernie \\ ${ }^{2}$ Siantan Supit \\ ${ }^{2}$ Joice N. A. Engka
}

\author{
${ }^{1}$ Kandidat Skripsi Fakultas Kedokteran Universitas Sam Ratulangi Manado \\ ${ }^{2}$ Bagian Fisologi Fakultas Kedokteran Universitas Sam Ratulangi Manado \\ Email: Bernie_bernardus@yahoo.com
}

\begin{abstract}
Gold is a mining commodity that has a high value. Tatelu's gold processing is traditionally done with tromol machines that produce high intensity continous noise. Noise is a trigger of stress, which is one of the causes of dyspepsia. This study aimed to find out the relationship between continous noise exposure of the mining tromol and dyspepsia complaints among Tatelu villagers. The study was done by using a cross sectional design. The samples were divided into two groups: the control and the exposed groups. Each group consisted of 20 people. Interviews used structured questionnaires, and dyspepsia diagnostics were based on Rome Consensus III. The characteristics of samples and the prevalence of dyspepsia complaints were assessed using univariate analysis. Chi square was used to assess the relationship between continous noise exposure of the tromols with complaints of dyspepsia. The results showed that in residential areas exposed to noise, $70 \%$ of the samples had complaints of dyspepsia, while in the control area there were only $25 \%$. The results of the statistical analysis using the Chi square showed the value $\mathrm{x}_{\text {count }}^{2}(8.12)>\mathrm{x}_{\text {table }}^{2}(3.84)$ and the $P$-value $=0.004<0.05$ with $\alpha<5 \%$. Conclusion: There was a significant relationship between the continous noise exposure from the gold tromols with the complaints of dyspepsia among Tatelu villagers.
\end{abstract}

Keywords: noise, stress, dyspepsia.

\begin{abstract}
Abstrak: Emas merupakan komoditi tambang yang mempunyai nilai tinggi. Pengolahan emas di desa Tatelu dilakukan secara tradisional dengan menggunakan mesin tromol yang menghasilkan bising kontinyu dengan intensitas tinggi. Bising merupakan pemicu terjadinya stres yang merupakan salah satu penyebab terjadinya dispepsia. Penelitian ini bertujuan untuk mengetahui hubungan pajanan bising kontinyu tromol emas terhadap keluhan dispepsia pada masyarakat desa Tatelu. Penelitian ini menggunakan rancangan cross sectional. Sampel terdiri dari 20 orang kelompok kontrol dan 20 orang kelompok terpajan. Penelitian menggunakan teknik wawancara dengan kuesioner terstruktur. Diagnosis dispepsia ditegakkan dengan kriteria Konsensus Roma III. Karakteristik sampel dan prevalensi keluhan dispepsia dinilai dengan analisis univariat. Hubungan antara pajanan bising kontinyu tromol emas dengan keluhan dispepsia dinilai dengan chi square. Hasil penelitian menunjukan pada daerah terpajan bising $70 \%$ sampel mengalami dispepsia sedangkan pada daerah kontrol hanya $25 \%$. Hasil analisis statistika dengan menggunakan chi square menunjukan nilai $\mathrm{x}_{\text {hitung }}(8,12)>$ $\mathrm{x}_{\text {tabel }}^{2}(3,84)$ dan nilai $P=0,004<0,05$ dengan $\alpha<5 \%$. Simpulan: Terdapat hubungan bermakna antara pajanan bising kontinyu tromol emas dengan keluhan dispepsia pada masyarakat Desa Tatelu.
\end{abstract}

Kata kunci: bising, stres, dispepsia. 
Emas merupakan salah satu komoditi tambang dengan nilai jual tinggi. Umumnya, emas tersebar secara tidak merata pada lapisan kulit bumi, sehingga diperlukan kegiatan pertambangan untuk mengelolanya. ${ }^{1}$ Kegiatan pertambangan padat dengan aktivitas peralatan tambang; hal tersebut menimbulkan suara yang mengganggu lingkungan terutama pemukiman yang berada di sekitar lokasi kegiatan pertambangan tersebut. ${ }^{2}$ Tromol emas merupakan salah satu contoh mesin pertambangan yang menghasilkan bising kontinyu dengan intensitas tinggi. $^{3}$ Tambang emas di Desa Tatelu merupakan daerah pertambangan emas tanpa izin operasional. Kegiatan pertambangan pada lokasi ini masih menggunakan sistem tradisional. ${ }^{4}$ Berdasarkan penelitian awal intensitas bising yang dihasilkan mesin tromol berada diatas ambang baku yang ditetapkan Menteri Negara Lingkungan Hidup Nomor: KEP-48/MENLH/11/1996. ${ }^{5}$

Bising merupakan bunyi yang tidak dikehendaki karena tidak sesuai dengan keadaan lingkungan sekitar sehingga menimbulkan gangguan kenyamanan dan kesehatan manusia. ${ }^{6}$ Pengaruh bising pada kesehatan dapat berupa gangguan pendengaran maupun yang bukan gangguan pendengaran. ${ }^{7}$ Gangguan bukan pendengaran yang dapat timbul antara lain gangguan tidur, menurunnya performa kerja, gangguan kardiovaskular, respon endokrin terkait bising, gangguan psikiatrik, dan kombinasi efek dari stresor lain. ${ }^{8}$ Emosi atau stres memengaruhi keadaan fisiologi saluran cerna, antara lain sekresi musinoid, pepsin, dan asam klorida lambung; diduga keadaan ini yang menjadi penyebab sindrom dispepsia. ${ }^{9}$

Dispepsia merupakan suatu sindroma yang terdiri dari nyeri atau rasa tidak nyaman di ulu hati, kembung, mual, muntah, bersendawa, rasa cepat kenyang, dan perut rasa penuh/begah. Tidak semua keluhan harus selalu terdapat pada setiap pasien, dapat bervariasi baik dari segi keluhan maupun kualitasnya. ${ }^{10}$ Keluhan dispepsia merupakan keadaan klinik yang sering dijumpai dalam praktek klinis sehari-hari, dan diperkirakan meliputi hampir 30\% kasus pada praktek umum dan $60 \%$ pada praktek gastroenterologist. Dari data pustaka negara Barat didapatkan angka prevalensi dispepsia berkisar 7-41\%, tetapi hanya $10-20 \%$ kasus yang mencari pertolongan medis. ${ }^{11}$ Frekuensi dispepsia yang belum tergolongkan dan dispepsia fungsional di Asia bervariasi antara $8-30 \% .^{12}$

Dispepsia merupakan masalah kesehatan tenaga kerja yang berdampak terhadap penurunan produktivitas tenaga kerja, yaitu berupa penurunan konsentrasi dari tenaga kerja akibat dispepsia. ${ }^{13}$ Penelitian mengenai hubungan pajanan bising kontinyu tromol emas dengan keluhan dispepsia belum pernah dilakukan sebelumnya. Hartono (2005) ${ }^{9}$ meneliti pengaruh perbedaan intensitas kebisingan terhadap sindroma dispepsia pada tenaga kerja Perseroan Terbatas Kusumahadi Santosa Karanganyar, sedangkan Pangemanan (2008) ${ }^{14}$ meneliti dampak bising kontinyu terhadap pendengaran pegawai di Pembangkit Listrik Tenaga Diesel (PLTD) Lopana Sulawesi Utara. ${ }^{14}$ Kedua penelitian ini dilakukan pada karakteristik masyarakat dan sumber bising lingkungan yang berbeda.

Berdasarkan uraian yang telah dikemukakan, maka penulis tertarik untuk meneliti hubungan pajanan bising kontinyu tromol emas dengan keluhan dispepsia pada masyarakat desa Tatelu.

\section{METODE PENELITIAN}

Penelitian ini menggunakan pendekatan cross sectional untuk mengetahui hubungan pajanan bising tromol emas dengan keluhan dispepsia pada masyarakat Desa Tatelu. Penelitian ini dilakukan di Desa Tatelu Kecamatan Dimembe Kabupaten Minahasa Provinsi Sulawesi Utara sejak bulan November-Desember 2012. Populasi penelitian ialah seluruh masyarakat desa Tatelu. Sampel penelitian terdiri dari 40 orang masyarakat Desa Tatelu. Sampel dibagi dalam dua kelompok, yaitu kelompok kontrol dan kelompok terpajan; masing-masing terdiri 
dari 20 orang. Pemilihan sampel menggunakan metode purposive sampling/ nonprobability sampling berdasarkan kriteria inklusi dan kriteria ekslusi penelitian. Kriteria inklusi penelitian ialah anggota masyarakat berusia 20-40 tahun dan telah tinggal di lokasi penelitian minimal dua tahun. Kriteria ekslusi ialah yang menggunakan NSAID, rutin mengonsumsi alkohol, kafein, dan makanan iritatif, bekerja secara langsung atau tidak langsung dalam kegiatan yang terkait dengan penggunaan merkuri, atau tidak bersedia dijadikan responden.

Penelitian ini dibagi menjadi dua pengamatan, yaitu pengamatan pada daerah kontrol dan pengamatan pada daerah pajanan bising tromol. Daerah pajanan bising dipilih daerah pemukiman penduduk di sekitar daerah operasional tromol emas. Daerah kontrol pada penelitian ini ialah wilayah jaga III yang berjarak $>1 \mathrm{~km}$ dari daerah pertambangan. Pemilihan daerah kontrol dengan jarak $>1 \mathrm{~km}$ bertujuan untuk menghilangkan efek pajanan suara bising lingkungan pertambangan.

Diagnosis dispepsia dilakukan berdasarkan kriteria Konsensus Roma III. Penentuan daerah kontrol dan terpajan bising dilakukan berdasarkan pengukuran tingkat bising sinambung menurut Keputusan Menteri Negara Lingkungan Hidup nomor: KEP-48/MENLH/11/1996, tentang metoda pengukuran, perhitungan dan evaluasi tingkat kebisingan lingkungan. Karakteristik sampel dan prevalensi keluhan dispepsia dinilai dengan analisis univariat menggunakan tabel distribusi frekuensi. Hubungan antara pajanan bising kontinyu tromol emas dengan keluhan dispepsia pada masyarakat Tatelu dinilai menggunakan chi square.

\section{HASIL PENELITIAN DAN BAHASAN}

Distribusi frekuensi keluhan dispepsia responden pada daerah kontrol dan terpajan bising dapat dilihat pada Tabel 1 . Responden yang memiliki keluhan nyeri ulu hati sebanyak 13 orang $(32,5 \%)$; keluhan ini merupakan keluhan terbanyak pada responden kelompok terpajan dan dari keseluruhan sampel.

Hasil analisis statistika hubungan pajanan bising kontinyu tromol emas dan keluhan dispepsia pada masyarakat Desa Tatelu dengan menggunakan chi square menunjukkan nilai $\mathrm{x}^{2}{ }_{\text {hitung }}(8,12)>\mathrm{x}^{2}$ tabel $(3,84)$, dan nilai $P=0,004<0,05$ dengan nilai $\alpha<5 \%$ (Tabel 2).

Tabel 1. Distribusi frekuensi keluhan dispepsia responden.

\begin{tabular}{ccccccc}
\hline Keluhan & \multicolumn{2}{c}{ Kontrol } & \multicolumn{2}{c}{ Terpajan } & \multicolumn{2}{c}{ Jumlah } \\
\cline { 2 - 7 } dispepsia & n & \% & n & \% & n & \% \\
\hline Rasa penuh & 2 & 10 & 5 & 25 & 7 & 17,5 \\
Cepat kenyang & 1 & 5 & 7 & 35 & 8 & 20 \\
Nyeri ulu hati & 4 & 20 & 9 & 45 & 13 & 32,5 \\
Mual & 5 & 25 & 7 & 35 & 12 & 30 \\
Muntah & 1 & 5 & 2 & 10 & 3 & 7,5 \\
Bersendawa & 1 & 5 & 5 & 25 & 6 & 15 \\
Kembung & 4 & 20 & 7 & 35 & 11 & 27,5 \\
\hline
\end{tabular}

Tabel 2. Hasil analisis hubungan pajanan bising kontinyu tromol emas dengan keluhan dispepsia pada masyarakat Desa Tatelu.

\begin{tabular}{ccccccccc}
\hline Status & \multicolumn{2}{c}{ Dispepsia } & \multicolumn{2}{c}{ Tidak Dispepsia } & \multirow{2}{*}{$\boldsymbol{P}$} & \multirow{2}{*}{$\mathbf{x}_{\text {hitung }}$} & $\mathbf{x}_{\text {tabel }}$ \\
\cline { 2 - 8 } Responden & $\mathbf{n}$ & $\mathbf{\%}$ & $\mathbf{n}$ & $\mathbf{\%}$ & & & & \\
\hline Terpajan & 14 & $70 \%$ & 6 & $30 \%$ & 0.004 & $5 \%$ & 8,12 & 3,84 \\
Kontrol & 5 & $25 \%$ & 15 & $75 \%$ & & & \\
\hline
\end{tabular}


Pengamatan bising pada tromol emas dipilih pada penelitian ini karena sifat bising yang kontinyu dan berintensitas sangat tinggi. Pengukuran bising dilakukan pada daerah pemukiman penduduk disekitar tromol emas dan pemukiman kontrol yang berjarak $>1 \mathrm{~km}$ dari lokasi pertambangan. Jenis kebisingan yang dihasilkan oleh tambang emas di Desa Tatelu pada lingkungan penelitian daerah terpajan bersumber dari mesin tromol emas. Kebisingan yang dihasilkan ini mengganggu komunikasi antar warga yang berada di sekitar lokasi tromol. Jumlah tromol yang bekerja secara serentak semakin menambah pajanan bising yang diterima warga disekitar lokasi tersebut.

Penghitungan tingkat kebisingan sinambung setara (equivalent continous noise level/Leq) menurut Keputusan Menteri Lingkungan Hidup nomor: KEP48/MENLH/11/1996 untuk siang malam pada daerah terpajan bising tromol emas ialah $85,2 \mathrm{~dB}$, artinya tingkat kebisingan di lokasi pemukiman yang berada disekitar mesin tromol emas di Desa Tatelu telah melebihi baku mutu tingkat kebisingan di perumahan yang ditetapkan oleh Peraturan Menteri Kesehatan RI Nomor: 718/MEN.KES./PER/XI/1987 tentang kebisingan yang berhubungan dengan kesehatan yang menyatakan tingkat kebisingan untuk lingkungan pemukiman masuk dalam zona B dengan tingkat kebisingan 45-55 dB. ${ }^{15}$ Penghitungan Leq pada daerah kontrol sebesar 51,7 dB, yang lebih rendah dibandingkan dengan daerah terpajan bising tromol karena lokasi daerah kontrol berjarak cukup jauh yakni $>1 \mathrm{~km}$ dari lokasi tambang.

Masyarakat berusia 20-40 tahun dipilih sebagai rentang usia sampel. Penduduk usia diatas 40 tahun tidak dimasukkan dalam penelitian ini karena pada usia diatas 40 tahun telah terjadi presbiakusis. ${ }^{14}$ Rentang usia 20-40 tahun dipilih karena kemudahan mengambarkan keluhan dispepsia yang dialami sehingga lebih mudah untuk mendiagnosis keluhan dispepsia dengan menggunakan kriteria Konsensus Roma III.
Kriteria inklusi pada setiap responden didapatkan dari pendataan dengan cara pengisian kuesioner. Subyek yang mengonsumsi alkohol, rokok, kafein, makanan iritatif tidak diikutsertakan dalam penelitian ini karena zat-zat tersebut dapat memerantarai terjadinya dispepsia. Subyek yang melakukan kegiatan yang berhubungan dengan merkuri baik secara langsung maupun tidak langsung, dikeluarkan dari pengamatan karena dapat berpotensi menimbulkan bias akibat intoksikasi merkuri. Subyek yang mengonsumsi obat-obatan dalam jangka waktu panjang terutama NSAID juga tidak diikutsertakan karena golongan obat ini memicu perdarahan lambung melalui penghambatan sistem siklooksigenase. ${ }^{16-18}$

Keluhan terbanyak baik secara total maupun penggolongan parsial antara kelompok pajanan dan kelompok kontrol ialah nyeri ulu hati. Hasil penelitian ini berbanding lurus jika dibandingkan dengan penelitian Ndraha di rumah sakit Koja Jakarta tentang gambaran endoskopik dan histologik pasien dispepsia. Prevalensi keluhan nyeri ulu hati pada masyarakat Desa Tatelu lebih rendah (45\%) dibandingkan dengan penelitian Ndraha $(91,2 \%) .{ }^{19}$

Hasil pengamatan menunjukkan bahwa responden yang mengalami dispepsia di daerah pemukiman yang terpajan bising sebesar $70 \%$, sedangkan untuk daerah kontrol $25 \%$. Terdapat hubungan yang berbanding lurus dengan penelitian Hartono sebelumnya yang menunjukkan dispepsia pada lingkungan produksi yang terpajan bising $69,5 \%$ dan pada lingkungan perkantoran sebesar $36,6 \%$ sebagai lingkungan kontrol. ${ }^{9}$ Tingginya prevalensi pada daerah terpajan bising disebabkan karena bising kontinyu berintensitas tinggi merupakan pemicu terjadinya stres. ${ }^{20}$ Stres memengaruhi sekresi fungsi lambung melalui dua jalur, yaitu jalur neurogen dan neurohormonal. Pada jalur neurogen, rangsangan konflik emosi pada korteks serebri memengaruhi kerja hipotalamus anterior, dan selanjutnya ke nukleus vagus, nervus vagus, dan lambung; sedangkan pada jalur neurohormonal, rangsangan pada 
korteks serebri diteruskan ke hipotalamus anterior, selanjutnya ke hipofisis anterior yang mengeluarkan kortikotropin. Hormon ini merangsang korteks adrenal untuk menghasilkan hormon adrenal yang merangsang produksi asam lambung. ${ }^{21}$

Hasil analisis statistik dengan menggunakan chi square menunjukkan bahwa nilai $\mathrm{x}_{\text {hitung }}^{2}(8,12)>$ dari $\mathrm{x}_{\text {tabel }}(3,84)$, sehingga hipotesis nol ditolak. Nilai $P=$ $0,004<0,05$ dengan nilai $\alpha<5 \%$ memperlihatkan terdapatnya hubungan bermakna antara pajanan bising tromol emas dan keluhan dispepsia yang muncul pada masyarakat Desa Tatelu.

Penelitian ini memiliki keterbatasan dalam kriteria diagnostik, yaitu hanya berdasarkan kriteria Konsensus Roma III. Pengontrolan variabel perancu hanya didasarkan pada pertanyaan penapisan, dan tidak dilakukan pemeriksaan biokimiawi kadar merkuri dan nilai ambang pendengaran.

\section{SIMPULAN}

Dari hasil penelitian dapat disimpulkan bahwa terdapat hubungan bermakna antara pajanan bising kontinyu tromol emas dan keluhan dispepsia pada masyarakat Desa Tatelu.

\section{UCAPAN TERIMA KASIH}

Ucapan terima kasih ditujukan kepada dr. Damajanty H.C. Pangemanan, M.Kes, AIFM dan dr. Sylvia R. Marunduh, M.Med, AIFM, AIFO selaku penguji skripsi, dan semua pihak baik secara langsung maupun tidak langsung telah menumbuhkan ide dan gagasan pada penulis.

\section{DAFTAR PUSTAKA}

1. Ahyani M. Pengaruh kegiatan penambangan emas terhadap kondisi kerusakan tanah pada wilayah pertambangan rakyat di Bombana Provinsi Sulawesi Tenggara [Tesis]. Semarang: Universitas Diponegoro; 2011.

2. Hidayat S, Purwanto, Hardiman G. Kajian tingkat kebisingan pertambangan yang diterima di area pemukiman sekitar tambang di desa Jaladri, Kecamatan Winongan, Kabupaten Pasuruan Jawa Timur. Prosiding Seminar Nasional Pengelolaan Sumber Daya Alam dan Lingkungan 11 September 2012, Semarang. [cited: 2012 Nov 2]. Available from: http://eprints.undip.ac. id/37626/1/09-Syarif_Hidayat.pdf

3. Luxson M, Darlina S, Malaka T. Kebisingan di tempat kerja. Jurnal Kesehatan Bina Husada. 2010;6(2):75-85.

4. Darmutji ST. Overview of project site in Talawaan and Galayan Areas [homepage on the Internet]. 2003 [cited 2012 Nov 5]. Available from: http://www. globalmercuryproject.org/Countries/ind onesia/docs/Indosite\%20overview.pdf

5. Keputusan Menteri Negara Lingkungan Hidup Nomor: Kep-48/MENLH/ 11/1996 tahun 1996 tentang Baku Tingkat Kebisingan.

6. Huboyo HS, Sumiyati S. Buku Ajar Pengendalian Bising dan Bau. Semarang: Universitas Diponegoro; 2008.

7. Rahayu T. Dampak kebisingan terhadap munculnya gangguan kesehatan. Jurnal WUNY. 2010: 59-65. [cited 2012 Nov 5]. Available from: http://staff.uny.ac. $\mathrm{id} /$ sites/default/files/Dampak\%20Kebisi ngan\%20terhadap \%20Munculnya $\% 20$ Gangguan\%20Kesehatan.pdf.

8. Stansfeld SA, Matheson MP. Noise pollution: non-auditory effect on health. British Medical Bulletin. 2003;68: 243-57.

9. Hartono. Pengaruh perbedaan intensitas kebisingan terhadap sindrom dispepsia pada tenaga kerja PT Kusumahadi Santosa Karanganyar. Jurnal Biosmart. 2005;7(2):131-4.

10. Djojoningrat D. Pendekatan klinis penyakit gastrointestinal. In: Sudoyo AW, Setiyohadi B, Alwi I, K Simadibrata M, Setiati S, editors. Buku Ajar Ilmu Penyakit Dalam Jilid 1 (Edisi Kelima). Jakarta: Interna Publishing, 2009; p. 441.

11. Djojoningrat D. Dispepsia fungsional. In: Sudoyo AW, Setiyohadi B, Alwi I, K Simadibrata M, Setiati S, editors. Buku Ajar Ilmu Penyakit Dalam Jilid 1 (Edisi Kelima). Jakarta: Interna Publishing, 2009; p. 529. 
12. Ghoshal UC, Singh R, Young C, Xiaohua $H$, Wong BCY, Kachintorn U. Epidemiology of uninvestigated and functional dyspepsia in Asia: Facts and fiction. JNM. 2011;17(3):244-53.

13. Soeripto. Penelitian pembuatan sumbat telinga. Majalah Hiperkes dan Keselamatan Kerja. 1994; 27(3):11-6.

14. Pangemanan DHC. Dampak bising kontinyu terhadap pendengaran (kajian terhadap ambang pendengaran dan gangguan pendengaran pada wanita di sekitar PLTD Lopana Sulawesi Utara) [Tesis]. Yogyakarta: UGM; 2008.

15. Peraturan Menteri Kesehatan RI Nomor 718/MEN.KES./PER/XI/1987 tentang Kebisingan yang Berhubungan dengan Kesehatan.

16. Kumar V, Cotran RS, Robbins SL. Buku Ajar Patologi (Edisi Ketujuh). Jakarta: EGC, 2007.

17. Rizkiani I. Pengaruh pemberian kopi dosis bertingkat peroral selama 30 hari terhadap gambaran histologi lambung tikus wistar [Skripsi]. Semarang: Universitas Diponegoro. 2009.

18. WHO. Exposure to mercury: a major public health concern. Switzerland; 2007. [cited 2012 Dec 20]. Available from: http://www.who.int/phe/news/Mercuryflyer.pdf.

19. Ndraha S, Simadibrata M. Upper gastrointestinal endoscopic and histopathological findings in patients with dispepsia. The Indonesian Journal of Gastroenterology Hepatology and Digestive Endoscopy. 2012;13(1):23-8.

20. Rylander R. Noise, stress, and annoyance. Sweden: Bio fact environmental health research center. 2006. [cited 2012 Dec 5]. Available from: http://www.doseresponse.org/news/Rylander.pdf.

21. Mujaddid E. Dispepsia fungsional. In: Sudoyo AW, Setiyohadi B, Alwi I, K Simadibrata M, Setiati S, editors. Buku Ajar Ilmu Penyakit Dalam Jilid III (Edisi Kelima). Jakarta: Interna Publishing; 2009. p. 2109. 